\title{
Analysis and Countermeasure Research on Graduate Employment Situation under the New Situation
}

\author{
Gang Li \\ Graduate School of Jilin Agricultural University, China
}

\begin{abstract}
With the popularization of higher education in our country, the employment of college graduates, especially graduates, has increasingly become the focus of attention of the community. The employment of graduates is a complicated and comprehensive problem, which involves all aspects of the school, the individual and the society. In this paper, a university in Guangzhou city is taken as an analysis of the case. This paper uses literature research and case studies, empirically analyzes the relevant data of the school's academic master graduates in the ten years from 2000 to 2010. Based on the case analysis of XX University, the author believes that the current local university academic master's degree graduate employment overall situation has a downward trend, and initially emerge structural unemployment phenomenon. Training school, graduates individuals and the government are the three main factor that influence graduates' smooth employment. Only by the joint efforts of these three aspects can promote local college graduates to obtain employment smoothly and achieve quality allocation of human resources. For local Colleges and Universities, it is necessary to adjust and optimize the graduate education discipline construction structure and the training methods and training objectives; graduates individuals should greatly enhance their employment competitiveness, the government should strengthen macro policy adjustment and support, including support based on local Colleges and Universities in actively expand the scale of professional degree, optimize the structure characteristic; establish warning mechanism of graduates supply and demand situation; introduce relevant policies to solve the problem of unbalanced economic development.
\end{abstract}

Keywords: Employment; Academic postgraduate; Local Colleges and Universities.

\section{Introduction}

At present, China's higher education has entered the era of popularization and the continuous expansion of graduate students resulted in that the employment of graduate students has gradually become a major social problem. At present, the whole country is in an important period of the regional industrial structure upgrading and the re-adjustment of talent space layout [1]. The scale of graduate education in local Colleges and Universities gradually grows, which undoubtedly plays an important role in serving the local economy and the high level of talent. Therefore, through the academic research on student's employment situation and characteristics of XX University, starts from the analysis of the impact of the graduate's employment nationwide, and then puts forward corresponding countermeasures and suggestions, which is of considerable significance [2]. This article, through first employment data analysis of academic type master graduates in a Guangzhou university, analyzed the factors influencing graduates employment, and put forward corresponding countermeasures, so as to provide some objective and worthy information and reference for the continuous healthy development of local Colleges and Universities graduates' education and smooth employment of the graduates, thus better guide local Colleges graduate education reform [3].

\section{Current Situation of Graduate Education in China}

\subsection{Expanding Speed and Scale of Graduates in China}

Since 1999, our country began to expand the enrollment of graduate students, graduate education develops rapidly in the country, and the scale is gradually expanded, especially in recent years. In 1999 the country recruit graduate students 7 thousand, while in 2000, it increases to 10 thousand, a 
growth of 43\% compared with 1999's. In 2001, the national recruit graduate students 13 thousand, with an increase of 3 thousand, about $26 \%$, as shown in table 1 and figure 1.

Table 1 Number of national graduates enrollment and scale statistic tables (unit/ten thousand)

\begin{tabular}{|c|c|c|c|c|}
\hline & \multicolumn{2}{|c|}{ Annual graduates enrollment } & \multicolumn{2}{c|}{ Graduate student scale } \\
\cline { 2 - 5 } & Enrollment number Annual growth rate & Number of students in school Annual growth rate \\
\hline 1999 & 7 & $25 \%$ & 18 & $27 \%$ \\
\hline 2000 & 10 & $43 \%$ & 23 & $30 \%$ \\
\hline 2001 & 13 & $26 \%$ & 30 & $31 \%$ \\
\hline 2002 & 16 & $23 \%$ & 39 & $27 \%$ \\
\hline 2003 & 22 & $34 \%$ & 51 & $32 \%$ \\
\hline 2004 & 27 & $24 \%$ & 65 & $27 \%$ \\
\hline
\end{tabular}

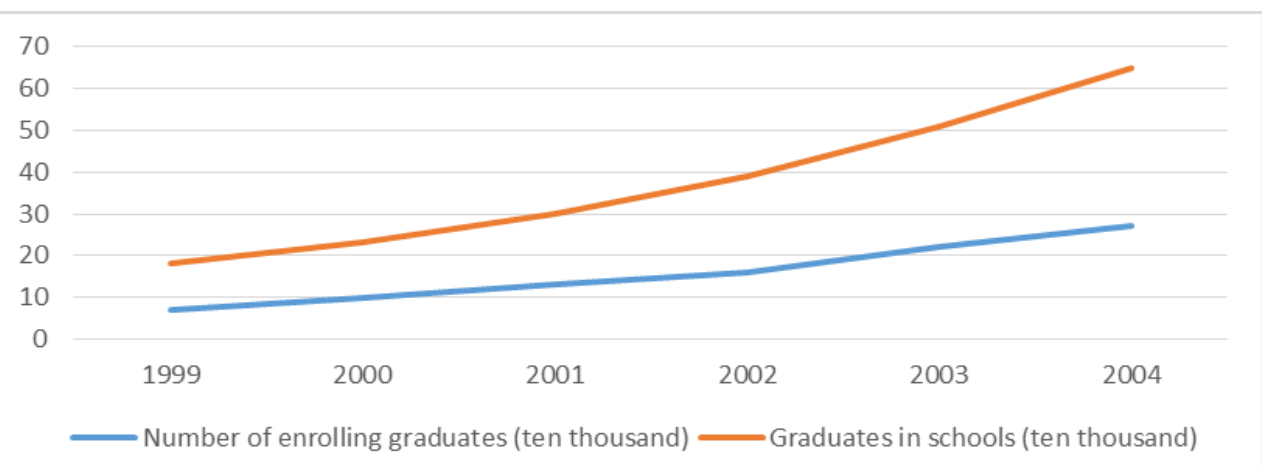

Figure 1 National graduates enrollment and in universities scale

\subsection{State of Employment of Graduates in the whole country}

In the case of the expansion of postgraduate enrollment scale year after year, the number of graduate students in the country has also become increasingly large. As shown in table 2 and figure 2, in 2000, the number of graduates is 6 thousand, by 2006 it reaches to 26 thousand, and it is 33 thousand in 2007. By 2008, it has increased to 30 thousand [4].

Table 2 Number of graduated graduates (units / ten thousand)

\begin{tabular}{|c|c|c|c|c|c|c|}
\hline Year & 2000 & 2001 & 2002 & 2003 & 2004 & 2005 \\
\hline Number of graduated graduates & 6 & 7 & 9 & 11 & 15 & 18 \\
\hline Annual growth rate & -- & $22 \%$ & $20 \%$ & $26 \%$ & $36 \%$ & $26 \%$ \\
\hline
\end{tabular}

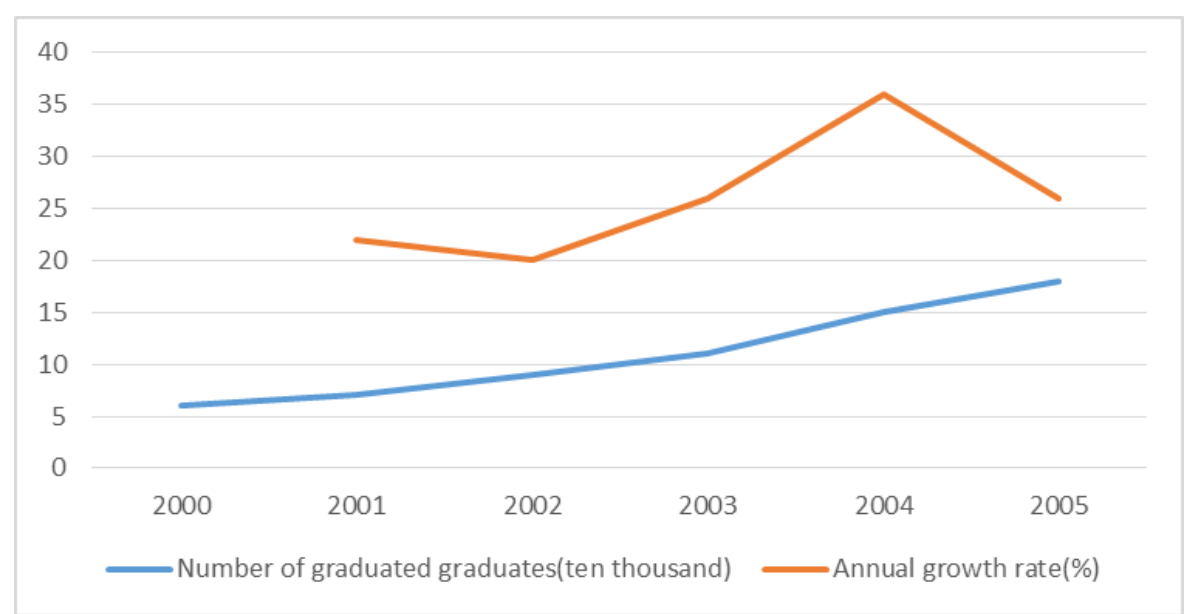

Figure 2 Number of graduated graduates

From the overall point of view, graduate employment rate decreased significantly. The number of graduated graduates was 90 thousand in 2002, the employment rate was $94.1 \%$. While in 2006, graduate employment rate has dropped to less than $90 \%$, and in 2007 , the number of graduated graduates was about 330 thousand, the employment rate further reduces to $84.2 \%$. Before 2005, the employment rate of the national graduate students were above $90 \%$. Since 2006, the graduate employment pressure gradually increased, and the employment rate continued to decline. 


\section{Empirical Analysis on the Employment of Academic Graduates in xx University}

\subsection{Basic Overview of the Development of Graduate Education in xx University}

During the period of "11th Five-Year", the scale of graduate students in xx University achieved rapid growth. As shown in table 3 and Figure 3, in 2000, the number of all kinds of graduate students in school is only 70 students, till April 2010, of all kinds of graduate students in school has increased to 2301 students [5]. For more than a decade, the number of graduate students has an average annual growth rate of about $22 \%$. With the expanding scale of graduate education enrollment, the number of graduated graduate student in xx University is also increasing year by year. In ten years, the number of graduate students in academic master's degree has increased by an average annual rate of about $28 \%$.

Table $3 \mathrm{xx}$ University academic master graduates basic information

\begin{tabular}{|c|c|c|c|}
\hline Year & Graduates in school & Number of enrollment & Number of the graduate \\
\hline 2000 & 70 & 40 & 5 \\
\hline 2001 & 120 & 50 & 25 \\
\hline 2002 & 160 & 70 & 40 \\
\hline 2003 & 210 & 90 & 50 \\
\hline 2004 & 340 & 180 & 70 \\
\hline 2005 & 500 & 220 & 90 \\
\hline 2006 & 820 & 250 & 220 \\
\hline 2007 & 1200 & 340 & 250 \\
\hline 2008 & 1500 & 450 & 320 \\
\hline 2009 & 1900 & 660 & \\
\hline
\end{tabular}

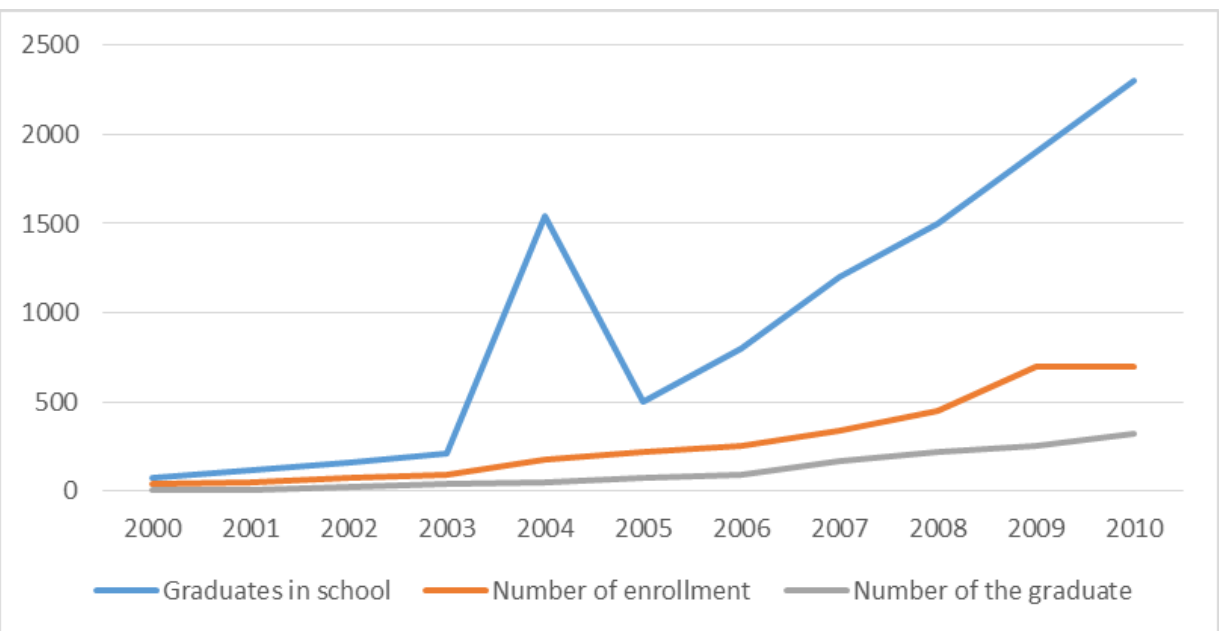

Figure 3 xx University academic master graduates basic information

\subsection{Analysis on the Employment Situation of Academic Graduates of xx University}

In order to further understand the $\mathrm{xx}$ University academic graduate employment situation, this thesis in the preparation stage collected the first employment data of 1191 academic graduate students of this school during 2000-2010, which is got from the school research office and the school, as shown in table 4 and figure 4.

Table $4 \mathrm{xx}$ University academic master degree graduates employment rate

\begin{tabular}{|c|c|c|c|c|c|c|c|c|c|c|c|}
\hline Year & 2000 & 2001 & 2002 & 2003 & 2004 & 2005 & 2006 & 2007 & 2008 & 2009 & 2010 \\
\hline Number of the graduate & 2 & 5 & 25 & 40 & 50 & 70 & 90 & 180 & 220 & 250 & 320 \\
\hline Employment rate & $100 \%$ & $100 \%$ & $100 \%$ & $100 \%$ & $100 \%$ & $99 \%$ & $96 \%$ & $93 \%$ & $92 \%$ & $90 \%$ & $89 \%$ \\
\hline
\end{tabular}




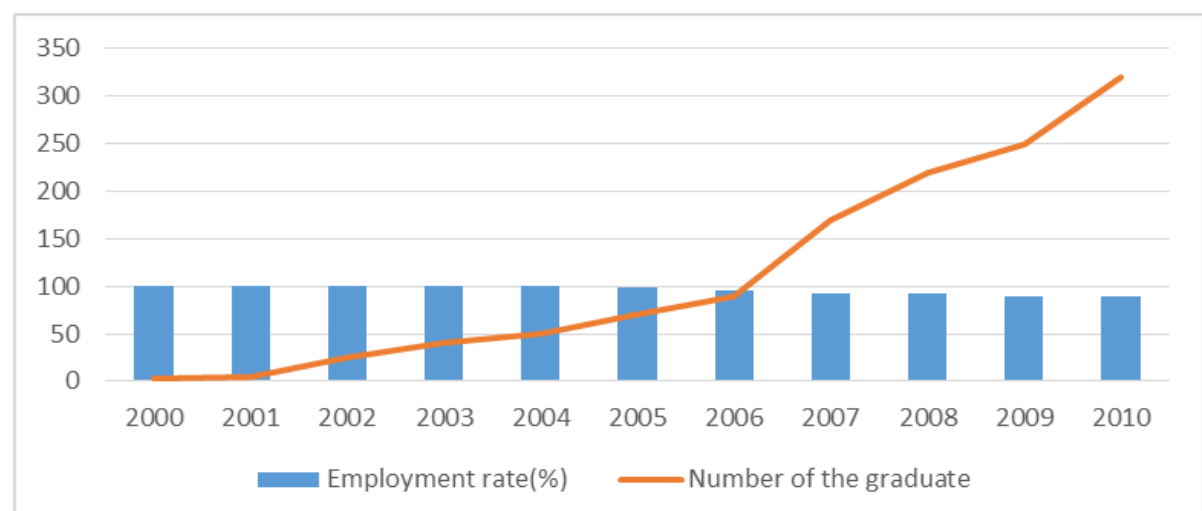

Figure 4 xx University academic graduates employment rate trend graph

\section{Countermeasures and Suggestions for the Employment of Local College Graduates}

Based on the analysis of the graduate employment situation, this paper does empirical research on academic graduate employment status of xx University. It is obvious that in the next few years, the graduate's employment is more and more difficult, and local Colleges and Universities graduate employment problem will become increasingly prominent. In order to alleviate the problem of graduate employment, this paper puts forward the following countermeasures and suggestions.

\subsection{Adjust the Structure of Discipline Construction and the Way of Training}

In "National medium and long term education reform and development plan" (2010-2020), it clearly put forward the idea of "to accelerate the development of professional degree graduate education, optimize the structure and develop the characteristics". Obviously, optimizing the structure is the important content and premise to improve the quality of graduate education, and it is the important foundation and inevitable requirement for the realization of the scientific development of graduate education [6]. Under the background of the graduate education popularization trend, the local Colleges and Universities must consciously adapt to the requirements of national policy and the market economy system, meet the demand of the development of education of national research and adjust disciplines and professional settings, vigorously develop social relief to the needs of the development of the popular professional, and appropriately reduce the professionals that is not appropriate for the market. In addition, for the local Colleges and Universities like xx University, the advantage is that the demand for the use of the market reaction is more sensitive, and it will be more effective in a professional degree [7]. Therefore, on the basis of maintaining the academic degree, local Colleges and Universities should actively expand the scale of professional degree, optimize the structure and develop the characteristics.

\subsection{Enhance the Competitiveness of Graduate Students' Employment}

The employment competitiveness of graduates is the key factor for the successful employment. Applying for postgraduate studies is to enhance the individual's comprehensive quality and ability. If the test is simply a stepping stone to the employment of the door, that is equivalent to the undergraduate employment pressure after 3 years. Therefore, it is necessary to correctly treat this problem. Once admitted, graduate students should seize the opportunity to study in the semester, and strive to improve the overall quality of the individual, so as to enhance the competitiveness of individual employment [8]. In addition, graduate student should do personal career planning as soon as possible, establish the development goal that suits oneself condition. Graduate students should be good at entering the job market, update the old thinking, try to adapt to the requirements of the talent market in the knowledge, ability, and ideas, and strive to enhance the competitiveness of individuals in the talent market.

\subsection{Strengthen the Adjustment and Support of the Government's Macro Policy}

Under the system of socialist market economy, the government should transfer functions as soon as possible, further improve the master graduates service system and employment policy and excellent employment environment in accordance with requirements of the establishment of the 
socialist market economic system. Establish the early warning mechanism of the supply and demand situation of postgraduates. In order to carry on the demand and supply situation of graduates in University and provide reference for the government decision-making and allocation of resources for higher education, the relevant government departments should launch students employment index system, including employment, employment gap and quality three indexes, and timely provide complete and accurate, quantitative and forward-looking employment information, so as to provide convenience for the communication among universities, graduates and employers.

\section{Conclusion}

Graduate employment problem relates to postgraduate training units, graduate students own quality, social policy and many other fields, which requires all aspects of society work together to actively participate in postgraduate training education system construction [9]. In recent years, with the continuous expansion of the enrollment scale of graduate students in local Colleges and Universities, the employment situation of postgraduates has a downward trend. To solve graduates employment problem, not only has certain practical significance for graduate student's personal development as well as harmony and stability for the entire campus and social and regional social and economic development [10]. Colleges need to actively promote and deepen the reform of education system on the basis of the existing educational resources; graduate students need to correct the learning motivation, actively change the concept of employment, establish a correct outlook on employment and market awareness, and actively adjust their mentality to adapt to the development of society; the government should play its leading role, strengthen macro-control and support. Only by the joint efforts can the problem of graduate's employment be well solved.

\section{References}

[1] Qu H. Influence of University Graduates Employment on Economic Growth and Its Statistical Forecast and Analysis [J]. Journal of Applied Sciences, 2013, 13(21): 4620.

[2] Chang, Lv Taizhi Li Chunchun Liu. Design and Realization of Graduates Employment Management Based on S2SH Framework. Computer \& Telecommunication 5 (2013): 039.

[3] LAI, Desheng, Dahu MENG, and Lifeng SU. Substitution or Complementation: A Study on Joint Mechanism of Human Capital and Social Capital to College Graduates' Employment [J]. Peking University Education Review 1 (2012): 006.

[4] Zhong X, Zhao-tuan H, Xiang-jun X I E. The Current Situation and Solutions of University Graduates Employment Instruction in the New Era [J]. China University Students Career Guide, 2014, 12: 013.

[5] Xucheng S, Yong Z, Liu Y. On the Current Situation of Higher Vocational College Graduates' Employment and the Countermeasures and Suggestions [J]. The Science Education Article Collects, 2014, 4: 122.

[6] Xi L. Discussion on College Graduates in Employment through Todaro's Model of Population Migration [J]. The Science Education Article Collects, 2014, 5: 004.

[7] Sheng G. Study of enhancing the employment competitiveness of non 985, 211 engineering college graduates-Taking Nanjing Audit University as an example [J]. Journal of Jiamusi Education Institute, 2013, 5: 134.

[8] del Mar Alonso-Almeida M, Marimon F, Casani F, et al. Diffusion of sustainability reporting in universities: Current situation and future perspectives[J]. Journal of cleaner production, 2015, 106: 144-154.

[9] Barreto S M, Miranda J J, Figueroa J P, et al. Epidemiology in Latin America and the Caribbean: current situation and challenges[J]. International journal of epidemiology, 2012, 41 (2): 557-571.

[10]Xuejun H, Jiayan C, Hong Y, et al. Analysis on the Employment Situation of Independent College Graduates: Taking One of the Zhejiang Independent Colleges as an Example [J]. The Science Education Article Collects, 2014, 11: 103. 